\section{Zu häufig Ermüdungsbrüche bei jungen Mädchen}

- Sport ist gesund, gerade auch für Kinder. Man kann es aber auch übertreiben, warnen Pädiater des Children's Hospital Boston. Sie sehen vor allem bei jungen Mädchen oft Ermüdungsbrüche. Werden diese zu spät erkannt und behandelt, drohen schwerwiegende Folgen.

Für die Growing Up Today Study wurden über 6800 Mädchen im Alter zwischen neun und 15 Jahren sieben Jahre lang beobachtet. In dieser Zeit entwickelten 4\% der Mädchen eine Ermüdungsfraktur. Betroffen waren vor allem Mädchen, die sich in Sportarten wie Laufen, Gymnastik, Basketball oder Cheerleading engagierten.

Bei Mädchen, die mehr als acht Stunden pro Woche Sport trieben, verdoppelte sich das Risiko, eine Ermüdungsfraktur zu erleiden. Eine sportliche Betätigung über mehr als 20 Wochenstunden war keine Seltenheit. Besonders ungünstig ist, wenn sich Kinder auf eine einzige Sportart spezialisieren. Einseitiges Training fördert das Risi-

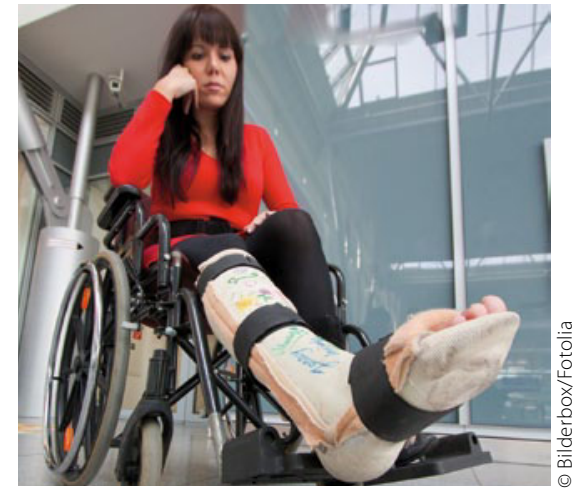

Zu lange und zu einseitig trainiert?

ko von Stressfrakturen zusätzlich. Bei Kindern sollte man sich Weisheiten wie "Training muss weh tun" verkneifen. Die Schmerzen könnten eben auch von einem Ermüdungsbruch herrühren. Diese heilen meist folgenlos ab, wenn man rechtzeitig eine Trainingspause einlegt.

$\mathrm{RM}=$

- Archives of Pediatric and Adolescent Medicine, 2011; DOI: 10.1001/archpediatrics.2011.34

ÜBERGEWICHTIGE SENIOREN?

\title{
Diät und Training stets im Doppelpack!
}

- Vernünftige Ernährung und viel Bewegung - dies ist das Patentrezept, um die körperliche Verfassung älterer Menschen zu verbessern. In einer Studie wurden 107 Über-65-Jährige, allesamt übergewichtig, in vier Gruppen eingeteilt: Die einen lebten weiter wie bisher, die zweiten erhielten eine kalorienarme Diät und die dritten nahmen an einem Trainingsprogramm teil. Bei der vierten Gruppe wurden beide Interventionen kombiniert. Nach einem Jahr schnitten alle drei Interventionsgruppen im Physical Performance Test besser ab als die Kontrollgruppe. Der Erfolg war jedoch in der Kombinationsgruppe mit einer Verbesserung um $21 \%$ am höchsten (gegenüber $12 \%$ unter Diät und $15 \%$ unter Training allein).

MO =

- N Engl J Med 2011;364:1218-29

\section{PHARMAKOTHERAPIE}

\section{Wird bittere Medizin bald geschmacklos?}

\section{Eitriger Auswurf sollte nicht zur Antibiotikagabe verleiten}

- Akuter Husten ist häufig viral bedingt. Gelb oder grün gefärbtes Sekret kann - neben länger als eine Woche anhaltender Symptomatik mit CRP-Erhöhung und Leukozytose - auf einen bakteriellen Infekt hinweisen. Bei ansonsten Gesunden sind jedoch laut der DGP-(Deutsche Gesellschaft für Pneumologie-)Husten-Leitlinie keine Antibiotika erforderlich. Empfohlen werden sie ggf. bei Komorbidität (koronarer Herzkrankheit, Diabetes mellitus, COPD, Immuninkompetenz bei Malignomen usw.) und/oder bei älteren Patienten.

In einer breit angelegten Studie wurde nun untersucht, wie das Verschreibungsverhalten von Ärzten in der Praxis aussieht. Dazu schlossen Wissenschaftler der Cardiff University 3402 Erwachsene aus 13 Ländern in ihre Studie ein. Patienten mit akutem Hus- ten, die farbigen Schleim produzierten, bekamen häufiger Antibiotika verschrieben (OR: 3,2; 95\%-Cl: 2,1-5,0) als Patienten mit trockenem Husten oder farblosem Auswurf (OR: 0,95, 95\%-Cl: 0,61-1,48). Einen signifikanten Einfluss auf die Krankheitsdauer hatte dieses Vorgehen jedoch nicht. Die Studienautoren plädieren deshalb dafür, Antibiotika nur Patienten zu verschreiben, die wirklich davon profitieren. So könnten unnötige Nebenwirkungen und die Entwicklung von Antibiotikaresistenzen vermieden werden.

KE -

- Eur Respir J. 2011 Mar 15 (published ahead of print), doi: 10.1183/09031936.00133910; Leitlinie der deutschen Gesellschaft für Pneumologie "Diagnostik und Therapie von erwachsenen Patienten mit akutem und chronischem Husten", aktualisierte Fassung 2010.
- Etwa 25\% aller Menschen sind sog. Superschmecker, d. h. sie reagieren besonders empfindlich auf Bitterstoffe. Betroffene können unter Umständen keine bittere Medizin schlucken, ohne sich zu übergeben. Und sie meiden bestimmte Nahrungsmittel, die eigentlich sehr gesund wären (z. B. Brokkoli), wegen der ihnen unangenehmen Bitterstoffe. Die Lebensmittelindustrie nutzt Fett, Salz oder Zucker, um den bitteren Beigeschmack in Konserven zu kaschieren, wobei diese Ingredienzien aus bekömmlichen eher unbekömmliche Lebensmittel machen.

Abhilfe könnten Hemmstoffe der Bitterrezeptoren schaffen. GIV3616, der neueste dieser Hemmstoffe, wirkt bereits in Konzentrationen von wenigen ppm und ist deshalb möglicherweise bekömmlicher als Salz, Zucker oder Fett.

$\mathrm{RM}=$

- Frühjahrstagung der American Chemical Society 27.-31. März, 2011, Anaheim, Kalifornien 